ITM Web of Conferences 2, 02002 (2014)

DOI: $10.1051 /$ itmconf/20140202002

(C) Owned by the authors, published by EDP Sciences, 2014

\title{
The influence of orographic features on wind farm efficiencies
}

\author{
C. Peralta ${ }^{\mathrm{a}}$, J. Schmidt ${ }^{\mathrm{b}}$, and B. Stoevesandt ${ }^{\mathrm{c}}$ \\ Fraunhofer IWES, Ammerländer Heerstr. 136, 26129 Oldenburg, Germany
}

\begin{abstract}
We employ Reynolds averaged Navier-Stokes (RANS) solvers for performing computational fluid dynamics (CFD) simulations of a neutral atmospheric boundary layer (ABL) for a wind farm located on a complex terrain. We also consider the influence of an adjacent hill/forest on the performance of the wind farm. We study an incompressible, isothermal, stationary wind field by solving the RANS equations using the $\mathrm{k}-\epsilon$ model. The forest canopy is included as a porous media, with trees of fixed height, using a porous media RANS solver. The presence of wind turbines is taken into account using an actuator disk model, extended for the whole wind farm.
\end{abstract}

\section{Introduction}

To a considerable extent, wind farms are usually located in windy, mid-latitude terrain. Sudden changes in wind direction and a strong turbulent field develop easily on mountainous or forested landscapes. A precise wind assessment for wind turbine siting can be very challenging in such situations. Sharp changes in wind fields in complex terrain can already occur at intervals of a few rotor diameters. Existing measurement methods are suitable only for the local assessment of wind conditions. Additionally, measurements on all potentially important variables can be very expensive. Current weather forecast models, on the other hand, do not have enough resolution for making accurate predictions on the scales of a typical wind farm $\left(\sim 20 \times 20 \mathrm{~km}^{2}\right)$. Therefore, it is currently quite common to recur to computational fluid dynamics (CFD) methods for performing wind site assessment in locations with a complex orography.

The numerical solution of the Reynolds Averaged Navier-Stokes (RANS) equations is the most widely used CFD method for $\mathrm{ABL}$ modeling in complex domains, due to its relatively cheap computational cost when compared to more sophisticated alternatives like large-eddy-simulation (LES). Additionally, RANS methods offer a better accuracy in the prediction of the flow field, which is difficult to achieve using standard wind prediction tools such as the Wind Atlas methodology [1].

Although there are many CFD commercial codes available, the open source finite volumes library OpenFOAM [2] has become a good alternative in recent times, in view of its good performance in complex terrain $[3,4]$. Additionally, the source code is freely available and relatively easy to modify,

\footnotetext{
a e-mail: carlos.peralta@iwes.fraunhofer.de

be-mail: jonas.schmidt@iwes.fraunhofer.de

ce-mail: bernhard.stoevesandt@iwes.fraunhofer.de
}

This is an Open Access article distributed under the terms of the Creative Commons Attribution License 2.0, which permits unrestricted use, distribution, and reproduction in any medium, provided the original work is properly cited. 


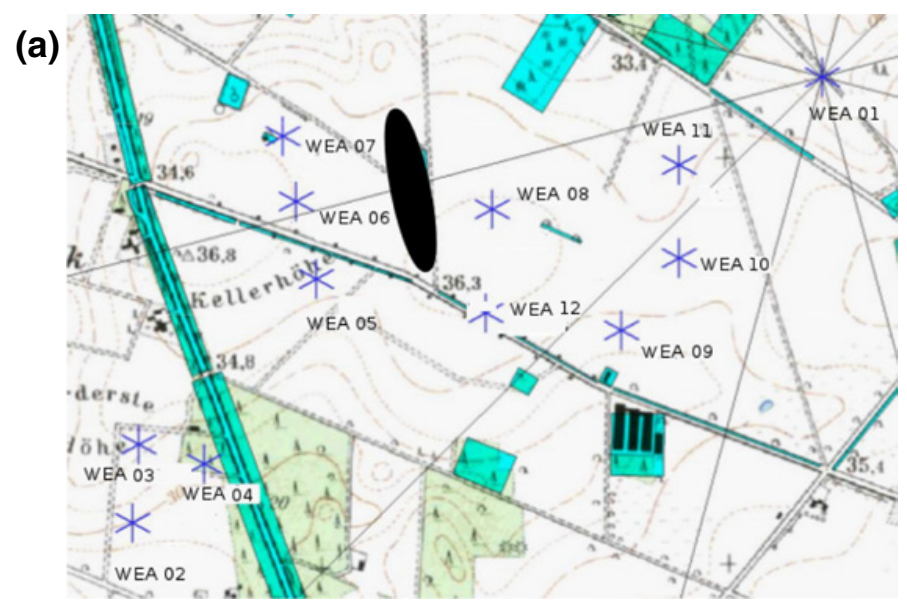

(b)

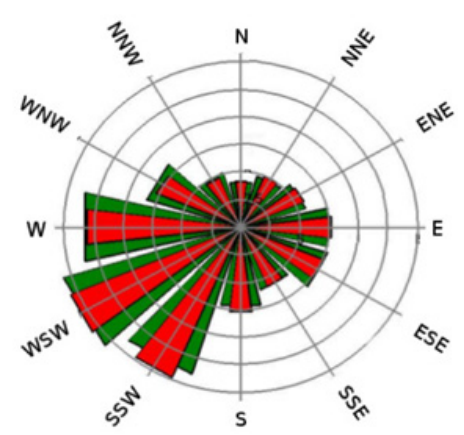

Figure 1. (a) Wind park Krumlande. The location of the wind turbines (WEA) is indicated by blue asterisks. The position of the landfill is indicated by a black elipse. (b) Wind conditions at the site Krumlande, $50 \mathrm{~m}$ height. The frequencies for each direction are presented in Table 1. (Adapted from [5].)

thanks to its highly object oriented implementation. This facilitates the implementation and modification of new solvers and libraries.

In this paper, we use OpenFOAM's simpleFoam (RANS) solver to perform CFD simulations of the wind field in a wind farm located in complex terrain. The windfarm studied consists of 12 Enercon wind turbines. An industrial disposal site is planned in the immediate vicinity of the wind farm. After filling, a mound of about $10 \mathrm{~m}$ height (or, equivalently, a forested terrain covering the landfill) will be present at the site. Our aim is to simulate 12 different wind directions (under neutral conditions), in order to have a complete overview of the wind field conditions on a particular location. These wind field estimates are then used to estimate the effect of the mound (or forested area) on the average power output of the wind turbines.

The paper is divided in 4 parts. In Section 2 we describe briefly the wind farm studied. In Section 3 we discuss the equations and the numerical method used to model the wind field in the complex orography. We discuss the results of the simulations in Section 4, and state some conclusions in Section 5.

\section{Wind farm studied}

A mineral landfill is planned in the surroundings of the community of Grossenkneten (Niedersachsen, Germany). The landfill is located at the former site of a sand mining area, next to the standing windpark Krumlande, with wind turbines of the type Enercon E-40 (turbines 2-7, see Figure 1a), E-66 (turbines 9-12), E-70 (turbine 1) and E-82 (turbine 8). In order to establish the influence of the landfill on the annual performance of the existing wind turbines, we perform steady-state CFD simulations. We consider 3 scenarios:

(A) Low lying grass cover at the location of the planned landfill area. This is the optimal option for the owners of the wind farm. The sand mining area will be filled and planted with a evenly distributed grass field.

(B) Consideration of the planned landfill. The landfill is completed and the resultant $(\approx 10 \mathrm{~m}$ height $)$ mound is planted with grass. 
(C) Situation after forestation of the landfill. As worst case scenario, the landfill is completed, and the flat surface at the location of the landfill planted with a forest $(\approx 13 \mathrm{~m}$ height).

In this study, these three scenarios are numerically simulated and compared for all the 12 wind directions of the wind rose (see Fig. 1b). The influence of the development scenarios on the wind farm is calculated by measuring the change in the power output of each wind turbine, obtained from the simulated data.

\section{Physics setup and solution method}

The equations solved are the steady state RANS equations for the wind field [6]. The presence of the turbines is modelled with actuator disks. The influence of the grass-filled area is modeled with wall functions [7], indicating the corresponding surface roughness length $z_{0}(\sim 0.03 \mathrm{~m})$. The landfill mound is modelled as a soft Gaussian hill with varying height [8].

\subsection{Mesh}

The local topography was modelled on a computational grid based on data provided by the State Office of Geographic Information and Land Development of Niedersachsen [9]. The equations are discretized in a computational domain of $2400 \mathrm{~m}$ in the flow direction, $2800 \mathrm{~m}$ in the cross direction and $300 \mathrm{~m}$ in the vertical direction. A structured grid is generated with the new library terrainBlockMesher [10], based on OpenFOAM's blockMesh native mesher. The new tool is capable of adding artificial orographic features. The landfill is modelled as an oval Gaussian hill of varying height, with peak height of $10 \mathrm{~m}$ [8]. We use 6,250,000 hexahedral cells for the simulations presented in this paper.

\subsection{Actuator disk model}

We follow the simplest actuator disk model derived from linear momentum theory, in which only an axial force is present. The kinetic energy extracted from the incoming air flow is a function of the thrust coefficient for a corresponding upstream wind speed [11]. The axial force is defined as

$$
F=-\frac{1}{2} \rho \pi R^{2} C_{t} U_{\infty}^{2}
$$

where $\mathrm{R}$ is the rotor radius, $U_{\infty}$ the upstream velocity (measured at an axial distance of $4 \mathrm{R}$ in front of the rotor), $C_{t}$ is the thrust coefficient for the incoming $U_{\infty}$ (extrapolated from tabulated values for each wind turbine) and $\rho$ is the air density. The actuator disk method has been shown to provide nearly identical predictions of velocity defect as more higher order methods like the actuator line outside the very near wake region [12]. This simple actuator disk model is therefore enough for evaluating the performance of the wind farm in this study, since only far wake wind speeds are important in this case.

\subsection{Forest model}

We use the mean flow model, which treats the forest as a porous media [13]. This model uses a modified Darcy-Forchheimer equation, as proposed in [14]. The viscous and inertial terms in the DarcyForchheimer equation are weighted by two empirical constants $c_{1}$ and $c_{2}$. In the simulations presented in this paper we use the tabulated values of $c_{1}=0.02 \mathrm{~s}^{-1}$ and $c_{2}=0.5 \mathrm{~m}^{-1}$ suggested in [13], and calibrated for a pine forest. An OpenFOAM-based tool (identifyForestCells [10]), based on the $\mathrm{C}++$ library OpenCV [15], is used to select the relevant porous cells representing the forest. An image of the location is given as input, indicating the forest region as a shaded area (see Fig. 1a). The "trees" are modelled as groups of cells of fixed height, selecting the corresponding cells near the patch representing 
the ground, as long as the maximal tree height $(13 \mathrm{~m})$, specified by the user in a dictionary, is not exceeded.

\subsection{Numerical method}

We use OpenFOAM's simpleFoam and porousSimpleFoam solvers, modified to include a wind farm based on the actuator disk model described in Section 3.2. The k- $\epsilon$ model is used for calculating the turbulent viscosity [16]. The following values of the model parameters are selected: $\kappa=0.42$, $C_{\mu}=0.033, \sigma_{k}=1.00, \sigma_{\epsilon}=1.30, C_{\epsilon 1}=1.18$, and $C_{\epsilon 2}=1.92$ [17].

We use OpenFOAM's ABL setup for the boundary conditions. It uses the Richards and Hoxey solution for the $\mathrm{k}-\epsilon$ model, which gives the following expressions at the inlet of computational domain for the velocity $\mathrm{U}$, turbulent kinetic energy $\mathrm{k}$, and turbulent dissipation rate $\epsilon$ for a neutral ABL [18]

$$
\begin{gathered}
U=\frac{u_{*}}{\kappa} \ln \left(\frac{z+z_{0}}{z_{0}}\right), \\
k=\frac{u_{*}^{2}}{\sqrt{C_{\mu}}}, \\
\epsilon=\frac{u_{*}^{3}}{\kappa\left(z+z_{0}\right)},
\end{gathered}
$$

where $u_{*}$ is the friction velocity and $\kappa$ the von Karman constant. This completely ignores thermal stratification. Coriolis effects are also ignored.

\subsection{Boundary conditions}

The boundary conditions are the following:

- Incomming flow (Inlet boundary): Dirichlet conditions for $\mathrm{U}, \mathrm{k}$, and $\epsilon$ given by the equations above (ie, fully homogeneous fully developed 2D profiles), using the OpenFOAM libraries atmBoundaryLayerInletVelocity and atmBoundaryLayerInletEpsilon. For pressure, a Neumann zero gradient condition is assumed.

- Outlet boundary. Flow is considered fully developed there, applying Neumann zero gradient condition for all variables, except for pressure. For this last variable a fixed (pressure $=0$ ) value is set.

- Sky (top boundary). Dirichlet conditions for $\mathrm{U}, \mathrm{k}$, and $\epsilon$, prescribing the values corresponding to the inlet profiles at the height of the computational domain. Additionally, one can also use slip conditions here: zero for the normal component of a vector, and zero gradient for tangential, zero gradient for any scalar.

- Ground (landscape terrain). Since we are only interested in modelling the inner region or constant stress layer, close to the viscous layer the variables are modelled via wall functions. We use wall functions for $\mathrm{k}$ and $\epsilon$. For $\mathrm{U}$, no slip is assumed, with a Neumann zero gradient condition for $\mathrm{p}$.

- Sides (parallel to the flow direction). Slip conditions are used on these boundaries, which are assumed oriented in the direction of the flow.

\section{Results}

We model the 12 wind directions with the method described in the previous section. With the resulting velocity fields we calculate the power curves for each wind turbine for each one of the cases described in Section 2. 
Table 1. Wind profile frequency (\%), and constants $u_{*}\left(\mathrm{~m} \mathrm{~s}^{-1}\right)$ and $U_{\text {ref }}\left(\mathrm{m} \mathrm{s}^{-1}\right)$, for each wind direction.

\begin{tabular}{l|l|l|l|l|l|l|l|l|l|l|l|l}
\hline \hline & E & ENE & NNE & N & NNW & WNW & W & WSW & SSW & S & SSE & ESE \\
\hline Freq. $(\%)$ & 4.2 & 5 & 5.9 & 7.7 & 7.6 & 5.8 & 7.7 & 14.8 & 15.7 & 13.0 & 7.8 & 4.8 \\
\hline$u_{*}\left(\mathrm{~m} \mathrm{~s}^{-1}\right)$ & 0.28 & 0.25 & 0.22 & 0.23 & 0.26 & 0.33 & 0.37 & 0.41 & 0.36 & 0.27 & 0.25 & 0.33 \\
\hline$U_{\text {ref }}\left(\mathrm{m} \mathrm{s}^{-1}\right)$ & 4.92 & 4.37 & 3.78 & 4.01 & 4.44 & 5.75 & 6.34 & 7.15 & 6.28 & 4.65 & 4.86 & 4.86 \\
\hline \hline
\end{tabular}
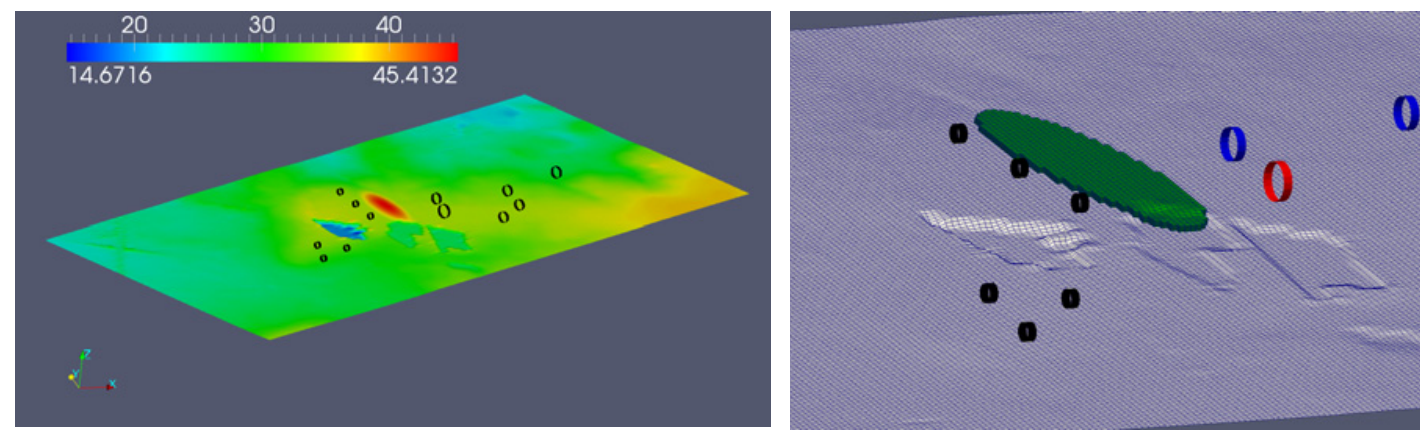

Figure 2. Elevation in meters (left) of the orography of the wind park under study. The red oval mountain represents the planned landfill mound (case A). The black ovals represent the actuator disks of the wind turbines. The incoming wind direction is WSW $\left(240^{\circ}\right)$. The figure on the right shows the position of the porous cells representing the alternaive forest position (case B). The black, blue and red disks are E-40 (65 m hub height), E-66 (98 m hub height) and E-82 (108.4 m hub height) wind turbines, respectively.
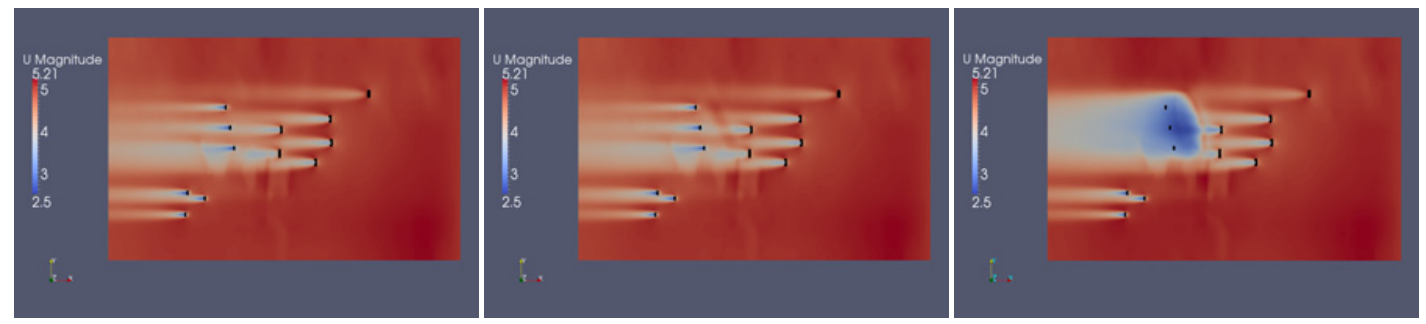

Figure 3. Magnitude of the wind speed (in $\mathrm{m} \mathrm{s}^{-1}$ ) at a height of $65 \mathrm{~m}$ for case A (left), B (center) and C (right). Incoming wind from the East direction.

\subsection{Simulation results}

Figure 2 (left) shows the location of the landfill in the simulation, represented by a red oval, for the simulation case (B). Figure 2 (right) shows the porous cells representing the forest, for the simulation case $(\mathrm{C})$. A steady state simulation of the wind field is performed before introducing the actuator disks. The simulations are stopped after a convergence of at least $1 \times 10^{-5}$ is achieved [4].

The wind conditions at the site Krumlande at $50 \mathrm{~m}$ height are described in [5]. The wind frequency for each wind direction in the windrose (Fig. 1b), based on a $10 \mathrm{yr}$ climatology, are indicated in Table 1. The most frequent wind direction is WSW (15.8\%). The values of $u_{*}$ and a reference velocity $U_{\text {ref }}$ at $50 \mathrm{~m}$ height, chosen for each wind direction are shown in Table 1.

For the wind direction East $\left(90^{\circ}\right)$ the wind turbines 5-7 are directly behind the landfill. This represents a counterpart of the wind direction WSW $\left(240^{\circ}\right)$, for which the wind turbines $5-7$ are on the windward side of the landfill. Figures 3-4 show horizontal cross sections for the magnitude of the wind speed for the simulated wind field at $65 \mathrm{~m}$ height. This corresponds to the hub height of turbines E-40. The effect of the landfill is evidenced by zones of reduced wind speed in front of and behind 

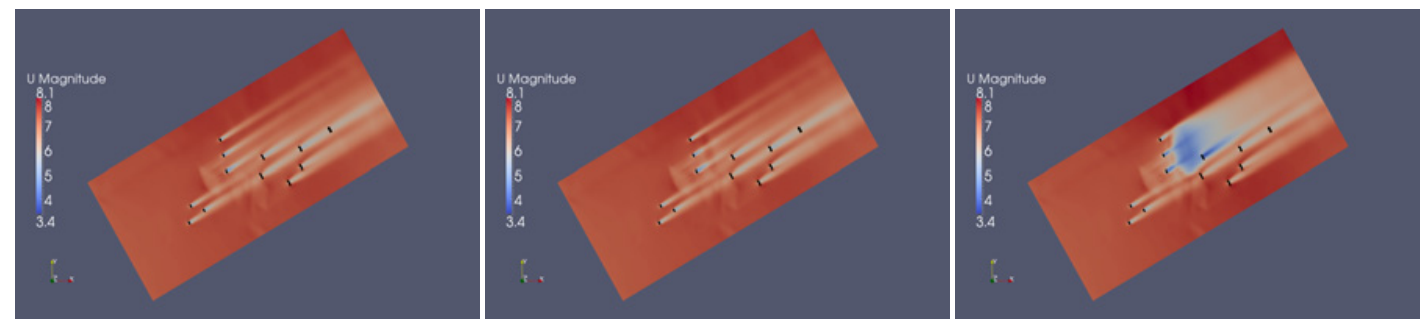

Figure 4. Magnitude of the wind speed (in $\mathrm{m} \mathrm{s}^{-1}$ ) at a height of $65 \mathrm{~m}$ for case A (left), B (center) and C (right). Incoming wind from the WSW direction.
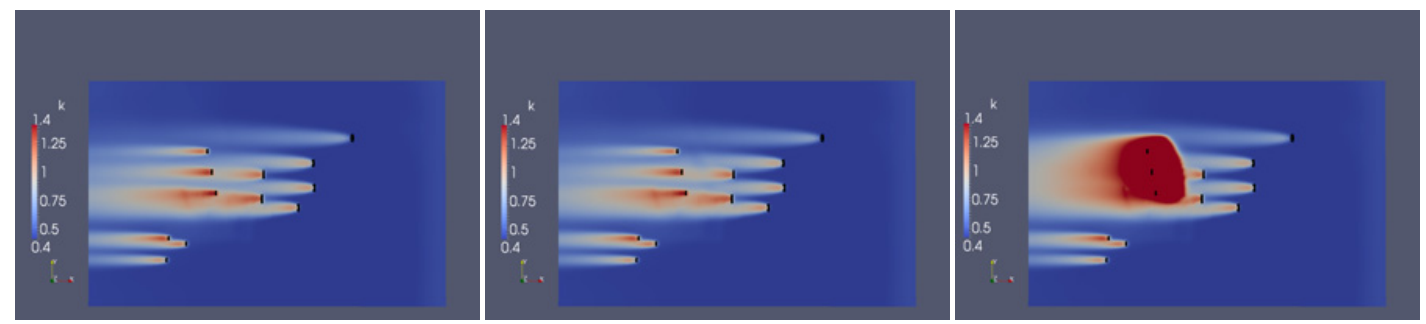

Figure 5. Turbulent kinetic energy (in $\mathrm{m}^{2} \mathrm{~s}^{-2}$ ) at a height of $65 \mathrm{~m}$ for case $\mathrm{A}$ (left), B (center) and C (right). Incoming wind from the East direction.
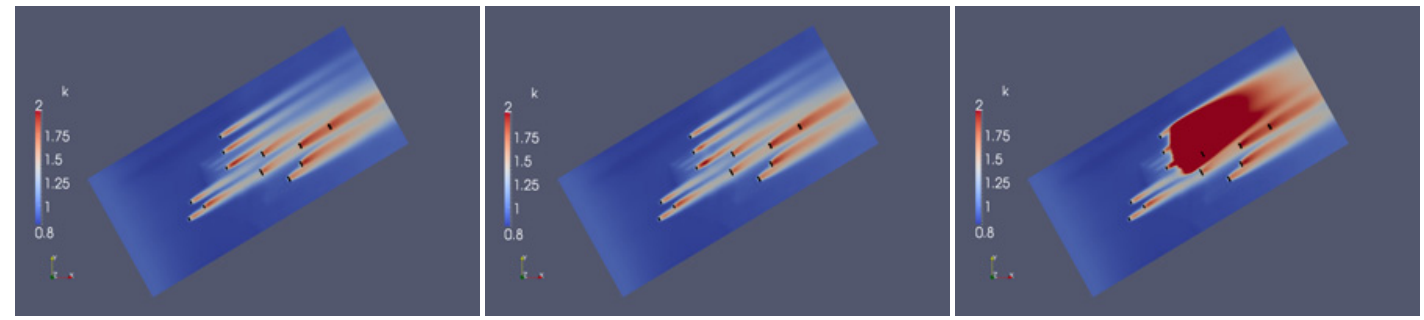

Figure 6. Turbulent kinetic energy (in $\mathrm{m}^{2} \mathrm{~s}^{-2}$ ) at a height of $65 \mathrm{~m}$ for case A (left), B (center) and C (right). Incoming wind from the WSW direction.

its center and acceleration directly above it. The magnitude of the wind velocity change can be up to $0.5 \mathrm{~m} \mathrm{~s}^{-1}$. Figures 5-6 show horizontal cross sections for the turbulent kinetic energy (TKE) at $65 \mathrm{~m}$ height. The maximum changes occur when the forest is present, with a particularly large effect on the row of turbines $5-7$. Turbine 7 experiences the largest change, with an $\sim 81 \%$ increase in TKE due to the presence of the forest.

\subsection{Estimates for the maximum annual yield losses}

From the results of the simulations presented in the previous section, we extract the local values of velocity at the incoming flow position $U_{\infty}$ for each turbine. The values are presented in Table 2. Each column shows the speed of the incoming flow in front of each wind turbine (estimated at 2 diameters in front of each rotor), for scenarios A, B and C. The values are calculated for every wind direction and weighted by the frequency of the wind speed on each wind direction (listed in Table 1). 
Table 2. Comparison of the mean wind speed $\langle v\rangle\left(\mathrm{m} \mathrm{s}^{-1}\right)$ and mean turbulent kinetic energy $\langle T K E\rangle\left(\mathrm{m}^{2} \mathrm{~s}^{-2}\right)$ at hub height for each wind turbine and wind direction for case $\mathrm{A}, \mathrm{B}$ and $\mathrm{C}$.

\begin{tabular}{l|l|ll|ll|lll}
\hline \hline Turbine number & Turbine type & \multicolumn{2}{|l|}{$\langle v\rangle$ and $\langle T K E\rangle$} & \multicolumn{2}{|l|}{$\langle v\rangle$ and $\langle T K E\rangle$} & \multicolumn{2}{|l|}{$\langle v\rangle$ and $\langle T K E\rangle$} \\
& & \multicolumn{2}{|l|}{ case A } & \multicolumn{2}{l|}{ case } & \\
\hline 1 & E-70 & 6.20 & 0.82 & 6.20 & 0.82 & 6.18 & 0.88 \\
\hline 2 & E-40 & 5.74 & 0.55 & 5.75 & 0.55 & 5.70 & 0.56 \\
\hline 3 & E-40 & 5.71 & 0.58 & 5.73 & 0.58 & 5.66 & 0.60 \\
\hline 4 & E-40 & 5.68 & 0.62 & 5.70 & 0.61 & 5.65 & 0.63 \\
\hline 5 & E-40 & 5.57 & 0.69 & 5.56 & 0.69 & 5.21 & 0.98 \\
\hline 6 & E-40 & 5.54 & 0.68 & 5.53 & 0.68 & 5.01 & 1.16 \\
\hline 7 & E-40 & 5.78 & 0.58 & 5.78 & 0.58 & 5.30 & 1.05 \\
\hline 8 & E-82 & 6.10 & 0.69 & 6.10 & 0.69 & 6.03 & 0.97 \\
\hline 9 & E-66 & 6.21 & 0.62 & 6.22 & 0.63 & 6.18 & 0.72 \\
\hline 10 & E-66 & 6.10 & 0.76 & 6.10 & 0.76 & 6.03 & 0.89 \\
\hline 11 & E-66 & 5.94 & 0.83 & 5.94 & 0.83 & 5.85 & 0.99 \\
\hline 12 & E-66 & 6.22 & 0.66 & 6.23 & 0.66 & 6.24 & 0.72 \\
\hline \hline
\end{tabular}

Table 3. Comparison of the relative change in the estimated annual energy yield, for each wind turbine and wind direction.

\begin{tabular}{l|c|c|c}
\hline \hline Turbine number & Turbine type & $\begin{array}{c}\text { Case B. } \\
\text { Yearly energy } \\
\text { loss relative } \\
\text { to case A. }\end{array}$ & $\begin{array}{c}\text { Case C. } \\
\text { Yearly energy } \\
\text { loss relative } \\
\text { to case A. }\end{array}$ \\
\hline 1 & E-70 & 0.24 & -0.98 \\
\hline 2 & E-40 & 0.66 & -1.60 \\
\hline 3 & E-40 & 0.80 & -2.42 \\
\hline 4 & E-40 & 0.94 & -1.56 \\
\hline 5 & E-40 & -0.39 & -18.64 \\
\hline 6 & E-40 & -0.29 & -27.59 \\
\hline 7 & E-40 & 0.15 & -22.28 \\
\hline 8 & E-82 & 0.03 & -4.63 \\
\hline 10 & E-66 & 0.65 & -2.06 \\
\hline 11 & E-66 & 0.28 & -4.39 \\
\hline 12 & E-66 & 0.20 & -4.58 \\
\hline \hline & E-66 & 0.69 & 1.50 \\
\hline
\end{tabular}

We use these values to calculate the power curves of each turbine and determine which turbine is most affected by the presence of the landfill mound (case B) or the forest (case C), as compared to the flat case (case A). We extrapolate the power $P$ from the power curve of each turbine [19], and calculate the yearly percentual loss in power with

$$
\frac{\Delta P_{B, C}}{P_{A}}=\frac{100\left(P_{B, C}-P_{A}\right)}{P_{A}},
$$

where $P_{A}, P_{B}$ and $P_{C}$ are the power from the wind turbine in scenarios $\mathrm{A}, \mathrm{B}$ and $\mathrm{C}$. The results are presented in Table 3, for each wind turbine. Although the numbers in Table 2 are similar for each scenario, the differences in output power for case $\mathrm{C}$ relative to case $\mathrm{A}$ can be large. Since the performance of a wind turbine below the rated output is proportional to the third power of the wind speed, it follows that the relative change in performance is $\Delta P / P=3 \Delta U / U$. The turbines most badly affected are usually located in the immediate vicinity of the obstacle: turbines 5,6 and 7 . For case $\mathrm{B}$ relative to $\mathrm{A}$, the effect is minimal, with all values below $1 \%$. However, for case $\mathrm{C}$ relative to $\mathrm{A}$ the reduction in performance can reach up to $\lesssim 28 \%$. In only one case, a small increase in performance ( $\lesssim 2 \%$, for turbine 12) is observed. 


\section{Conclusions}

The subject of this investigation was to compare three different building scenarios for a part of the domain of the wind farm Krumlande. We compared a flat, grassy area, an oval hill and forested area of identical size. The hill represents the construction of a mineral landfill and the forested area was planned in the original development of the site. We used steady state RANS simulations with the k- $\epsilon$ model for the turbulence closure, and represented the wind turbines as actuator disks. The incoming flow was given as a logarithmic wind profile for neutral atmospheric stratification. The local topography was modeled in a structured grid in which the landfill mound was incorporated. The forest was modelled as cells of fixed porosity, using a mean flow model.

The three scenarios were simulated numerically using the simpleFoam solver for 12 wind directions. In this way we could estimate the effects on the performance of the surrounding wind turbines. A flattened landfill is the optimal case. The forested area is the worst case scenario, producing a decrease of almost $28 \%$ for the wind turbines located immediately next to the landfill area. Our estimates for the loss in energy production due to the landfill site are similar previous studies wich used the Wind Atlas methodology [19], but they greatly differ from their estimates on the influence on the forest, especially on the turbines closest to the planned disposal site. The forest introduces a fairly large increase in the TKE that affects most the turbines in its direct vicinity. Turbines 5-7 experience up to $81 \%$ increase in TKE, and up to $28 \%$ drop in power.

There are several shortcomings in this investigation. The forest model is very simple, and does not include any anisotropy, neither it takes into account important quantities usually included in canopy models, like the leaf area index. Extensions of the model in this direction, considering for example modifications on the turbulence model due to the forest canopy are being planned [13]. Additionally, the simulations considered only a neutrally stratified ABL. Topographical and thermal stratification are the major cause of local wind resource site variations. Theferefore, there is still need to consider stable and unstable stratification and compare with available wind data.

The terrain studied in this investigation is fairly flat (maximum peaks at $\sim 50 \mathrm{~m}$ ). For more complex terrain, the terrainBlockMesher capabilities have been extended. In particular, the option to refine the mesh in regions with more complex orography is already available [20]. An example can be found in [21], where the mesher was used in the classical Askervein [22] and Bolund [23] data sets, and the simpleFoam solver was validated. The fully structured nature of the mesh makes it suitable for use in LES simulations. A full validation of the actuation disk solver developed for this investigation will be presented in a future paper.

We thank the owners of the Krumlande windfarm for providing data on the layout and meteorological reports of the windfarm studied in this paper.

\section{References}

[1] I. Troen, E.L. Petersen, European Wind Atlas, Published for the Commission of the European Communities, Brussels, Belgiumm by RIS $\varnothing$ National Laboratory, Roskilde, Denmark, ISBN 87550-1482-8, 656 pp. (1989)

[2] The OpenFOAM Foundation, http: ://www. openfoam.org

[3] A. Bechmann, J. Berg, M. Courtney, J. Mann, N. Sørensen, The bolund experiment: Blind comparison of cfd codes - wind in complex terrain, RisøTechnical report (2009)

[4] B. Martínez, Master's thesis, RISØ DTU, Denmark (2011)

[5] J. Michalk, R.M. Marksfeldt, Windgutachten und Parkwirkungsgradberechnungen für den Standort Krumlande, IEL GmbH, Aurich, Germany (2010) 
[6] S.B. Pope, Turbulent Flows (Cambridge University Press, Cambridge, UK, 2000)

[7] B. Blocken, T. Stathopoulos, J. Carmeliet, Atmospheric Environment. 41, 238 (2007)

[8] A.E. Kasmi, C. Masson, Wind Energy 13, 689 (2010)

[9] Landesvermessung und Geobasisinformation, http://www . lgn.niedersachsen.de

[10] J. Schmidt, C. Peralta, B. Stoevesandt, Automated generation of structured meshes for wind energy applications, Open Source CFD International Conference, London (2012)

[11] J.F. Manwell, J.G. McGowan, A.L. Rogers, Wind Energy Explained (Wiley and Sons, UK, 2009)

[12] N. Troldborg, F. Zahle, P.E. Réthoré N. Sørensen, American Institute of Aeronautics and Astronautics. Meeting Papers on Disc 4, 3407 (2012)

[13] X. Cai, Master's thesis, Technische Universität München (2011)

[14] G. Crasto, Ph.D. thesis, Università degli Studi di Cagliari (2007)

[15] Open Source Computer Vision, http://opencv.willowgarage.com/wiki/

[16] B.E. Launder, D.B. Spalding, Mathematical Models of Turbulence (Academic Press, London., 1972)

[17] J. Sumner, C.S. Watters, C. Masson, Energies 3, 989 (2010)

[18] P.J. Richards, R.P. Hoxey, J. Wind Eng. Ind. Aerod. 46, 145 (1993)

[19] R. Cordsen, Ermittlung des Einflusses einer Mineralstoffdenponie auf bestehende Windenergieanlagen in Bezug auf den mittleren jährlichen Energieertrag, Staubentwicklung und Repowering-Möchlichkeiten am Standort Döhlen., Overspeed GmbH, Oldenburg, Germany (2012)

[20] J. Schmidt, terrainBlockMesher, https://github.com/jonasIWES/terrainBlock Mesher

[21] C. Peralta, H. Nugusse, S.P. Kokilavani, J. Schmidt, B. Stoevesandt, Validation of the simpleFoam (RANS) solver for the atmospheric boundary layer in complex terrain, First Symposium on OpenFOAM in Wind Energy (2013)

[22] P.A. Taylor, H.W. Teunissen, Boundary-Layer Meteorology 39, 15 (1987)

[23] J. Berg, J. Mann, A. Bechmann, M.S. Courtney, H.E. Jørgensen, Boundary-Layer Meteorology 141, 219 (2011) 